\title{
Non-invasive staging of liver fibrosis by two-dimensional shear wave elastography (2D-SWE) in patients with chronic hepatitis $C$ and $B$
}

\author{
Ahmed M. Alsowey ${ }^{*}$ and Samar M. Shehata
}

\begin{abstract}
Background: Non-invasive shear wave-based techniques have been developed for estimating liver fibrosis in patients with chronic liver diseases. Two-dimensional shear wave elastography provides in real-time, a tow dimensional quantitative map of tissue stiffness and enables measuring the stiffness by adjustment of a region of interest of tissue. The aim of this study was to highlight the role of tow dimensional shear wave elastography (2DSWE) in detecting the degree of liver fibrosis in patients with chronic hepatitis $C$ and $B$, in correlation with liver enzymes level and fibrotest.

Results: This study included 50 patients with chronic hepatitis C and B whose ages were (range, 30-65 years; mean, 48 years). Shear wave elastography cutoff values were $1.35 \mathrm{~m} / \mathrm{s}, 5.48 \mathrm{KPa}$ for $(F>0) ; 1.66 \mathrm{~m} / \mathrm{s}, 8.29 \mathrm{kPa}$ for $(\mathrm{F}>1) ; 1.77$ $\mathrm{m} / \mathrm{s}, 9.40 \mathrm{kPa}$ for $(\mathrm{F}>2)$; and $1.99 \mathrm{~m} / \mathrm{s}, 11.9 \mathrm{kPa}$ for $(\mathrm{F}>3)$. An excellent agreement was found between shear wave elastography and Fibrotest in staging of liver fibrosis in $88 \%$ of patients $\left(K_{w}=0.943,95 \% \mathrm{Cl}, 0.88\right.$ to 1.00$)$ achieving a highly statistical significance $(P<0.001)$. There was a significant moderate positive concordance between US scoring and staging by 2D-SWE and staging by Fibrotest $\left(r_{s}, 0.49 ; P<0.01\right)$ and $\left(r_{s}, 0.48 ; P<0.01\right)$ respectively. However, no significant concordances were noticed between staging by AST and ALT and 2D-SWE and staging by Fibrotest ( $P>0.05)$.
\end{abstract}

Conclusions: 2D shear wave elastography showed better diagnostic performance than visual assessment by conventional US for detection of chronic liver diseases, as well as for evaluation of their severity and prognosis. Elastograhy-Fibrotest combination gives best diagnostic performance in detecting the degree of fibrosis noninvasively and can be used reliably as a first-line pre-therapeutic evaluation of fibrosis in HCV and HBV-infected patients.

Keywords: Shear wave elastography, Liver fibrosis, Fibrotest

\section{Background}

Chronic liver diseases are major public health concerns, with an estimated mortality of 1.5 million per year worldwide due to cirrhosis and its complications. The assessment of liver fibrosis is a key element to determine prognosis, to manage treatment, to monitor disease

\footnotetext{
*Correspondence: ahmedalsowey@yahoo.com

Department of Radiodiagnosis, Zagazig University, Zagazig, Egypt
}

progression and assess response to therapy in patients with chronic liver disease $[1,2]$. The precise staging of hepatic fibrosis is an essential predictor of disease outcome and influences the indication for antiviral therapy [1].

A variety of markers have been evaluated for their ability to assess liver fibrosis. The histo-pathologic examination of a liver specimen obtained by percutaneous biopsy has traditionally been considered as the gold

\section{Springer Open}

(c) The Author(s). 2021 Open Access This article is licensed under a Creative Commons Attribution 4.0 International License, which permits use, sharing, adaptation, distribution and reproduction in any medium or format, as long as you give appropriate credit to the original author(s) and the source, provide a link to the Creative Commons licence, and indicate if changes were made. The images or other third party material in this article are included in the article's Creative Commons licence, unless indicated otherwise in a credit line to the material. If material is not included in the article's Creative Commons licence and your intended use is not permitted by statutory regulation or exceeds the permitted use, you will need to obtain permission directly from the copyright holder. To view a copy of this licence, visit http://creativecommons.org/licenses/by/4.0/. 
standard for detecting the degree of hepatic fibrosis [3, 4]. The most widely used histological score for liver fibrosis is the METAVIR (Meta-analysis of Histological Data in Viral Hepatitis) score, which incorporates five stages of fibrosis: F0 (no fibrosis), F1 (portal fibrosis without septa: minimal fibrosis), F2 (portal fibrosis with a few septa: moderate fibrosis or clinically significant fibrosis), F3 (portal fibrosis with many septa but no cirrhosis: severe fibrosis), and F4 (cirrhosis) [5, 6]. However, this procedure is invasive, painful, and may lead to hemorrhage $(0.3 \%)$ or death $(0.01 \%)$. In addition, the biopsy analysis depends on the experience of the pathologist, the site of sampling and the size of the biopsy sample (usually about 1/50,000 of the total liver mass) [7]. Liver biopsy is also an invasive and painful procedure, and it is not accurate enough due to sampling errors and intra- and inter-observer variability, it has up to a $20 \%$ error rate in disease staging thus may result in over or under estimation of fibrosis stage. In addition, it is certainly not the suitable procedure for serially repeated assessment of disease progression [810].

The need for non-invasive tools that accurately measure the degree of liver fibrosis has been rising. The latest technological advancement in this setting is ultrasound elastography that estimates the liver stiffness by measuring the velocity of elastic shear waves in the liver parenchyma produced by the mechanical push where the propagation velocity is directly related to the stiffness of the medium $[11,12]$.

Multiple shear wave-based techniques have been developed for estimating liver fibrosis in patients with chronic liver diseases such as FibroScan (transient elastography, TE), and acoustic radiation force impulse (ARFI) [12]. Several studies have reported good performances of TE in patients with hepatitis $\mathrm{C}$ or hepatitis B (virus infections) [13, 14]. However, TE does not allow measuring stiffness in patients with ascites and fails in up to $20 \%$, particularly when body mass index (BMI) is high [15]. ARFI has the advantage to provide a steerable point estimate of liver

Table 1 US scoring of liver fibrosis among the studied cases

\begin{tabular}{lll}
\hline $\begin{array}{l}\text { Ultrasound } \\
\text { cumulative } \\
\text { scoring }\end{array}$ & $\mathbf{( N = 5 0 )}$ & $\%$ \\
\cline { 2 - 3 } Score 3 & No. & 8 \\
Score $\mathbf{4}$ & 4 & 24 \\
Score $\mathbf{5}$ & 12 & 12 \\
Score $\mathbf{6}$ & 6 & 20 \\
Score $\mathbf{7}$ & 10 & 12 \\
Score 8 & 6 & 16 \\
Score 9 & 8 & 8 \\
\hline
\end{tabular}

tissue stiffness, guided by ultrasound with diagnostic performances similar to histopathologic analysis [16, 17]. Two-dimensional shear wave elastography (2DSWE), also named super-sonic shear imaging provides in real-time, a 2D quantitative map of tissue stiffness and enables measuring the stiffness by adjustment of a region of interest (ROI) of tissue (up to $4 \mathrm{~cm}$ long, $4 \mathrm{~cm}$ wide) $[18,19]$.

Fibrotest (FT) is the most frequently used serum biomarker for liver fibrosis, it consists of an algorithm of five fibrosis markers (alfa2-macroglobulin, apolipoproteinA1, haptoglobin, GGT, bilirubin), it was initially validated in patients with chronic hepatitis $\mathrm{C}(\mathrm{CHC})$ and subsequently tested in other common liver diseases, including chronic hepatitis B (CHB), alcoholic liver disease (ALD), and non-alcoholic fatty liver disease (NAFLD). In patients with $\mathrm{CHC}, \mathrm{CHB}$, or ALD, FT has been found to have a higher or comparable prognostic benefit compared to hepatic biopsy [20, 21].

The aim of this study was to highlight the role of 2dimensional shear wave elastography (2D-SWE) in detecting the degree of liver fibrosis in chronic hepatitis $\mathrm{C}$ and $\mathrm{B}$ patients, in correlation with liver enzymes level and Fibrotest.

\section{Methods \\ Subjects}

The study included 50 patients referred from the tropical and internal medicine departments (30 males and 20 females, their ages ranged from 30 to 65 years with mean age of 48 years) from October 2019 to June 2020. After obtaining institutional review board approval from our institution and informed consent from the patients, all patients underwent laboratory tests (liver enzymes and Fibrotest), conventional ultrasonography, and shear wave elastography of the liver. Two radiologists with 15 years of experience in abdominal imaging and 6 years of experience in elastography techniques were conducted in the study. The interpretation of the result was carried out separately.

\section{Inclusion criteria}

1. Patients of both genders with chronic viral hepatitis ( $\mathrm{C}$ and $\mathrm{B}$ ) before antiviral therapy for identification of the degree of hepatic fibrosis.

\section{Exclusion criteria}

1. Patients with morbid obesity.

2. Females in late pregnancy.

3. Patients with tense ascites.

4. Patients with hepatocellular carcinoma. 


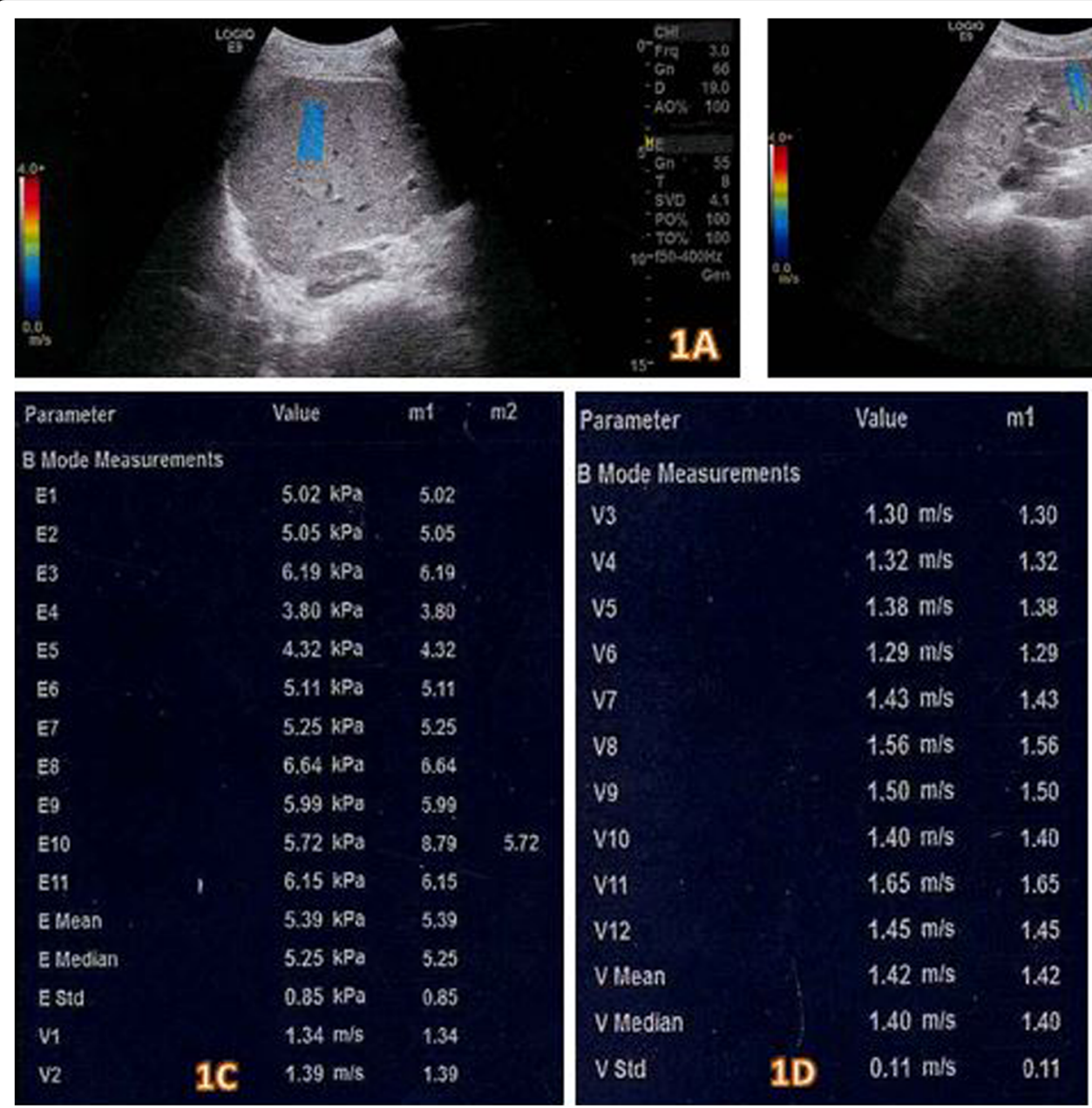

Fig. 1 FO stage: A male patient aged 48 years old with HCV chronic hepatitis and normal AST and ALT. Conventional US reveals the following (a and b): Liver > s smooth surface (score 1), homogeneous echopattern (score 1), smooth hepatic veins (score 1) "cumulated score 3." No ascites, top normal spleen size, normal portal vein caliber, single GB stone. $2 \mathrm{D}$ shear wave elastography $(\mathbf{c}$ and $\mathbf{d})$ : Velocity median value $=1.40 \mathrm{~m} / \mathrm{s}$. Stiffness median value $=5.25 \mathrm{kPa}$. Fibrotest result was 0.23 denoting F0-F1 stage $(\mathbf{e})$

5. Patients with inadequate breath hold and inaccurate elastography measurements.

\section{Radiological assessment \\ Patient preparation}

- Fasting for 4 hours. The normal liver is very compliant, so a non-fasting patient with a normal liver will likely have normal elastographic findings. However, the fibrotic liver is less compliant and in the non-fasting state can have falsely increased elastography values.

\section{Conventional B-mode ultrasound examination of the liver}

Patients were lying supine on an examination table and were sometimes turned to left lateral side to improve the image quality. A warm water-based gel was applied to the upper quadrant region and the transducer was moved back and forth over the area of interest until the desired images are captured using the routine protocol for liver US, which consisted of subcostal views of the left lobe, subcostal and intercostal views of the right lobe, subcostal views of the bifurcation of the portal vein, and subcostal views of the hepatic veins. US scoring were determined in each patient as described by Kim JE et al. [22] depending on liver surface nodularity score, liver parenchyma echo-texture score, and hepatic vein contour score.

The cumulative score was calculated as the sum of the three scores, it ranged from 3 (for a normal liver) to 9 (for advanced cirrhosis). Score 1 for smooth hepatic surface, homogeneous parenchymal echo texture and smooth hepatic veins. Score 2 for wave form hepatic surface, mildly coarse parenchymal echo texture, and irregular wall hepatic veins with normal caliber. Score 3 for irregular nodular hepatic surface, coarse parenchymal echo texture 

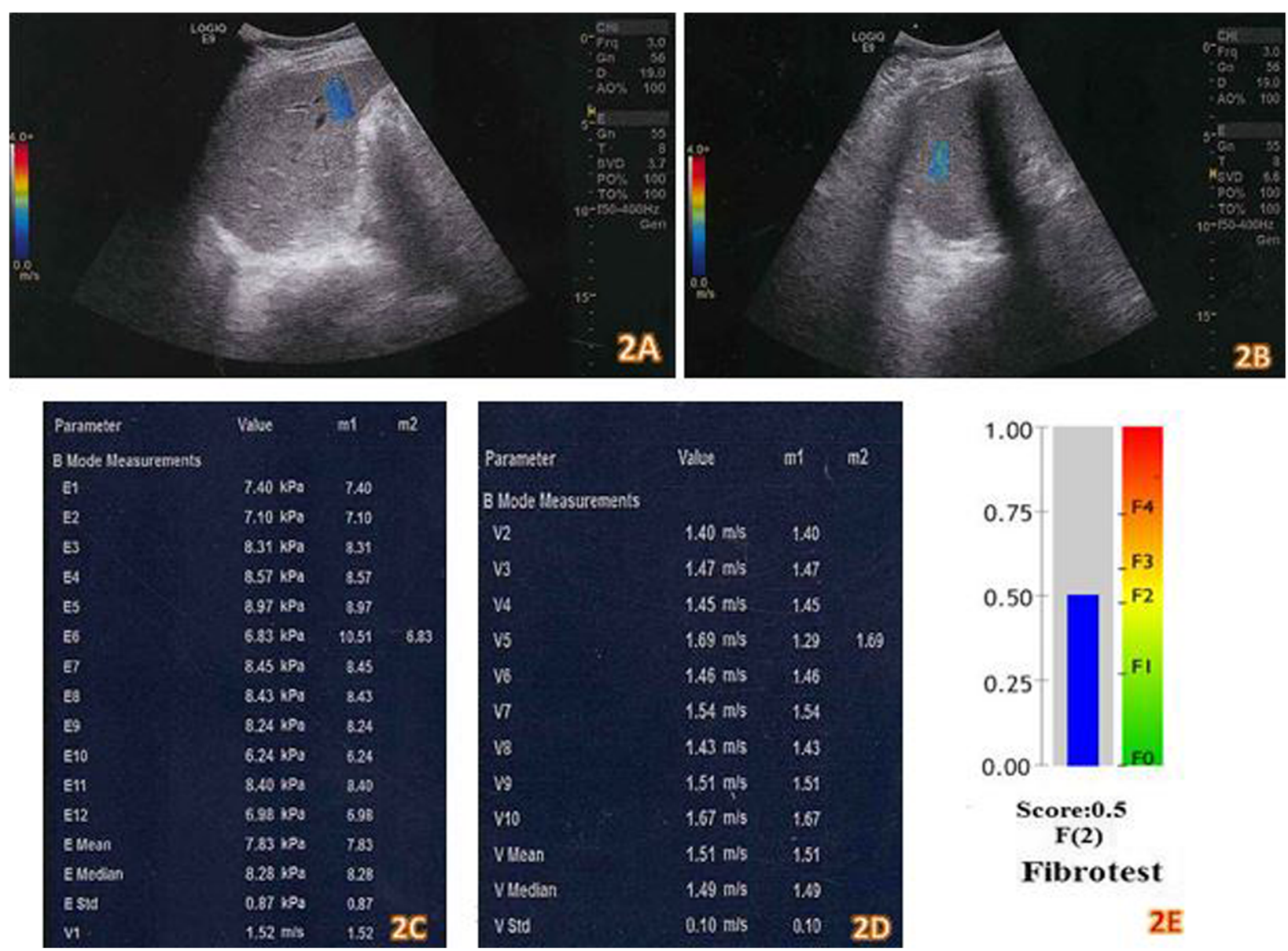

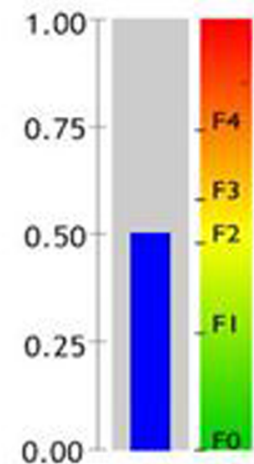

\section{Score:0.5 $\mathbf{F}(2)$ \\ Fibrotest}

\section{$2 \mathrm{E}$}

Fig. 2 F0-F1 stage: A female patient aged 38 years old with HCV chronic hepatitis and elevated AST and ALT. Conventional US reveals the following (a and b): Liver >> wave form surface (score 2), mildly coarse echopattern (score 2), smooth hepatic veins (score 1) "cumulated score 5." No ascites, normal spleen size, dilated portal vein caliber $(14 \mathrm{~mm})$. 2D shear wave elastography $(\mathbf{c}$ and $\mathbf{d})$ : Velocity median value $=1.49 \mathrm{~m} / \mathrm{s}$. Stiffness median value $=8.28 \mathrm{kPa}$. Fibrotest result was 0.5 denoting F2 stage $(\mathbf{e})$

with reticular pattern, and irregular wall hepatic veins with narrowed caliber.

\section{Shear wave ultrasound elastography examination}

Shear wave elastography data in the liver was acquired using a GE Healthcare (LOGIQ E9) system with the R5 software version and the C1-6-D probe. This application is able to capture the propagation of the resulting SW in real-time and in a large area of liver parenchyma, developing a real-time color-coded elasticity imaging. Quantitative measurements were performed in the color window by placing one or more ROI inside the sample box. During the B-mode sonographic examination of the liver, a standardized ROI box (fan-shaped, up to $50 \times 50$ $\mathrm{mm}$ ) is positioned in a predetermined anatomical site within the liver parenchyma and the velocity of the wave propagation, expressed in meters per second $(\mathrm{m} / \mathrm{s})$ or kilopascals $(\mathrm{KPa})$, was calculated. The cutoff values used for interpretation of $2 \mathrm{D}$ shear wave elastography findings were $1.35 \mathrm{~m} / \mathrm{s}$ velocity median value and $5.48 \mathrm{kPa}$ stiffness median value respectively for F0, $1.66 \mathrm{~m} / \mathrm{s}$ and 8.29 $\mathrm{kPa}$ respectively for $\mathrm{F} 1,1.77 \mathrm{~m} / \mathrm{s}$ and $9.4 \mathrm{kPa}$ respectively for $\mathrm{F} 2$ and $1.99 \mathrm{~m} / \mathrm{s}$ and $11.9 \mathrm{kPa}$ respectively for F3/F4.

\section{The technique of shear wave ultrasound elastography examination}

The right arm of the patient was placed in maximum abduction to enlarge the space between the ribs. During SWE acquisition, the patient was asked to stop breathing for 5 s. The elastographic acquisition was repeated 5 times for each patient. For each acquisition, a real-time SWE 2D color map of the stiffness (in $\mathrm{kPa}$ ) was frozen after stabilization for at least $3 \mathrm{~s}$ [23-25].The placement of the SWE color map could be moved, enabling an extended visual evaluation of liver stiffness. The subcapsular region was avoided because reverberation artifacts are often found beneath the capsule of Glisson. Similarly, perivascular areas were avoided because they may 

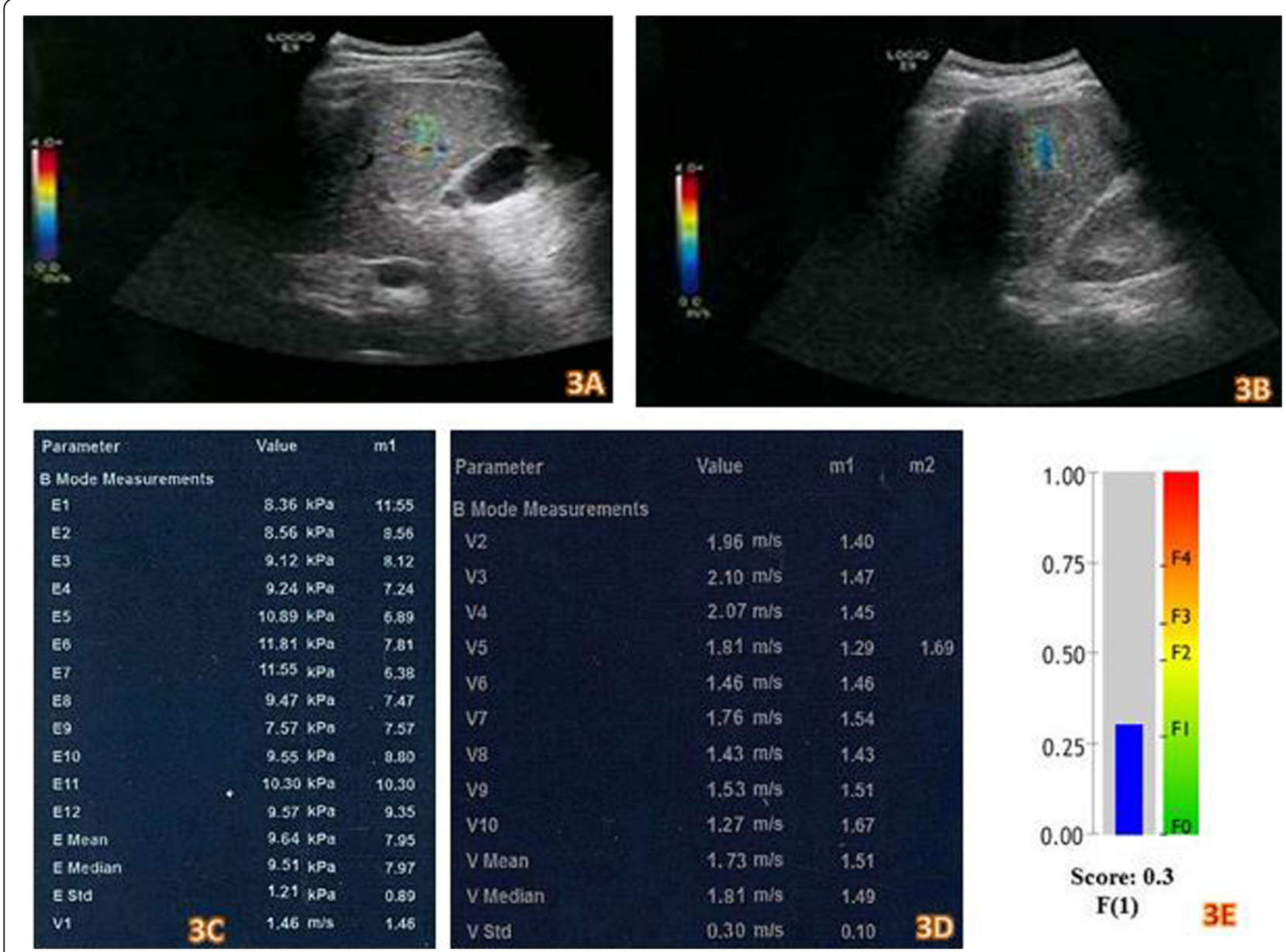

Score: 0.3

$\mathbf{F}(1)$

Fig. 3 F2 stage: A male patient aged 43 years old with HBV chronic hepatitis and elevated AST and ALT. He is also a known cardiac patient presented with tachypnea. Conventional US reveals the following ( $\mathbf{a}$ and $\mathbf{b}$ ): Liver > >smooth surface (score 1), coarse with reticular pattern (score 3), smooth hepatic veins (score 1) "cumulated score 5." Minimal ascites, normal spleen size, normal portal vein caliber. 2D shear wave elastography (c and $\mathbf{d}$ ): Velocity median value $=1.80 \mathrm{~m} / \mathrm{s}$. Stiffness median value $=9.51 \mathrm{kPa}$. Fibrotest result was 0.3 denoting F1 stage (e)

alter liver stiffness estimate $[19,20]$. The stiffness was calculated as the median of several SWE successful measurements.

An acquisition was considered to be successful if the following criteria were fulfilled:

- The SWE color box filled more than 2 thirds of the total SWE box surface.

- The elastographic signals within the vessels were missed.

- The minimal stiffness was superior to $0.2 \mathrm{kPa}$ in the ROI.

\section{Laboratory investigations}

1Liver enzymes (ALT and AST).

2Fibo-test combines several indirect serum fibrosis markers for staging fibrosis in chronic viral hepatitis including: $\alpha 2$-macroglobulin, haptoglobin, GGT, apolipoprotein $\mathrm{A} 1$, and total bilirubin, adjusted for gender and age in a patented artificial intelligence algorithm in order to generate a measure of fibrosis. The fibrosis staging was determined using score $(f)$ described by Ratziu V et al. [26] which involves five stages (F0-F4); values of Fibrotest range from 0 to 1 where values more than 0.58 indicate advanced fibrosis and more than 0.74 indicate severe fibrosis.

\section{Statistical analysis}

Data were analyzed by Statistical Package of Social Science (SPSS), software version 24.0 (SPSS Inc., 2016). Continuous data were presented as the mean \pm SD if normally distributed or median (range) if not normally distributed. Categorical data were presented by the count and percentage. The strength of concordance and agreement were assessed using weighted kappa $\left(\kappa_{\mathrm{w}}\right)$ and the Spearman's rho correlation coefficient $\left(r_{s}\right) . P$ values $<0.05$ indicates significant, $P<0.01$ indicates highly significant difference. 

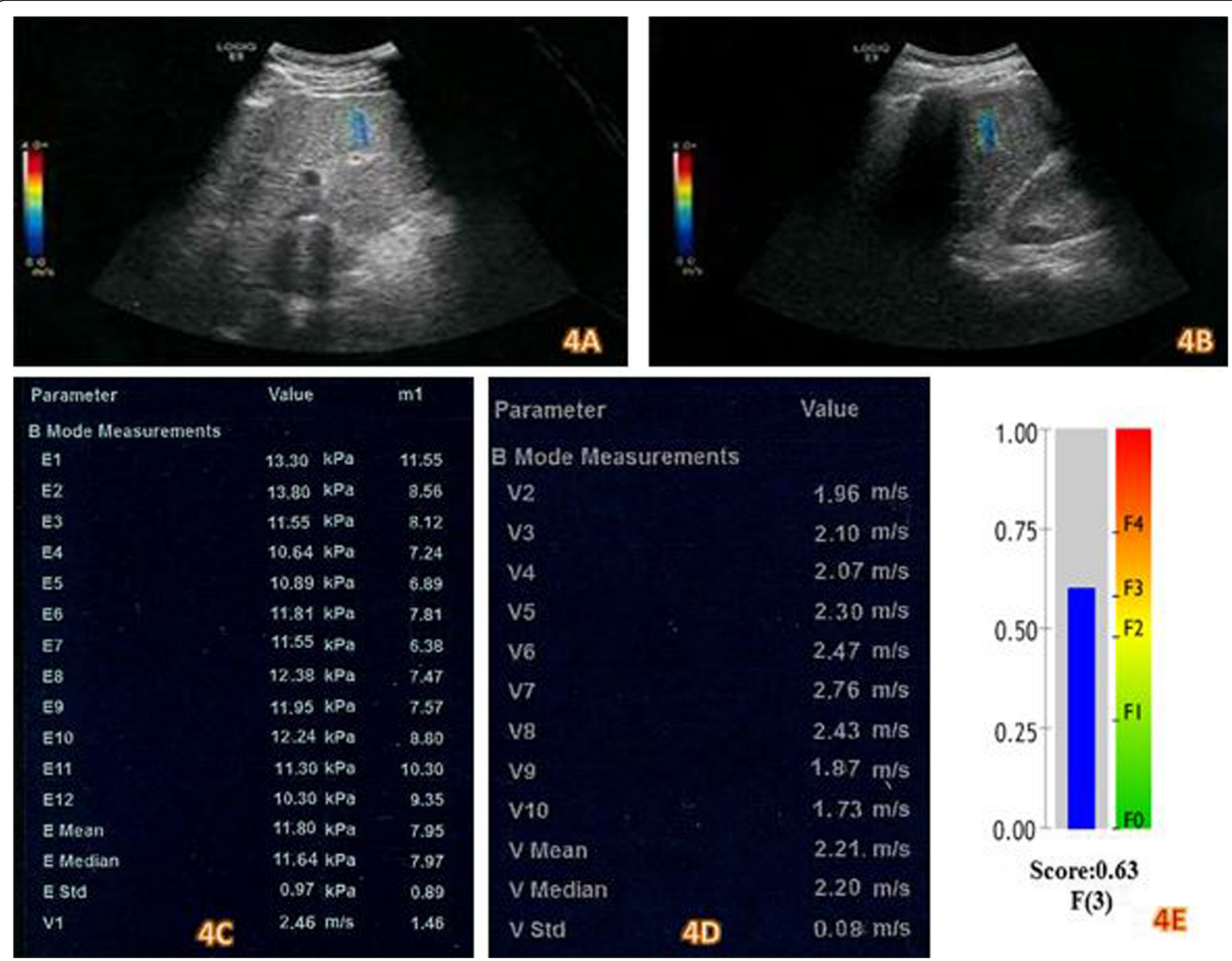

Fig. 4 F3 stage: A male patient aged 57 years old with HCV chronic hepatitis and slightly elevated AST and ALT. Conventional US reveals the following (a and $\mathbf{b}$ ): Liver >> wave form surface (score 2), coarse with reticular pattern (score 3), hepatic veins with irregular wall, and normal caliber (score 2) "cumulated score 7." Mild ascites, enlarged spleen size (longitudinal axis=160 mm), dilated portal vein caliber (14.6 mm), multiple GB stones. 2D shear wave elastography ( $\mathbf{c}$ and $\mathbf{d}$ ): Velocity median value $=2.20 \mathrm{~m} / \mathrm{s}$. Stiffness median value $=11 \mathrm{kPa}$. Fibrotest result was 0.63 denoting F3 stage (e)

\section{Results}

\section{Study population}

From 57 patients referred to elastography unit, 7 patients were excluded due to inadequate breath hold $(n=4)$ and inaccurate elastography measures $(n=3)$. Finally, the study included 50 patients with chronic hepatitis C and B (60\% males, $40 \%$ females) whose ages were (range, 30-65 years; mean, 48 years). They presented with flu-like symptoms (fatigability, joint pain, anorexia; $24 \%$ ), abdominal pain $(32 \%)$, jaundice $(16 \%)$, and steatorrhea (12\%), the remaining cases had no symptoms just for follow-up (20\%). Conventional ultrasonography and shear wave elastography were performed to all patients after liver enzyme tests and Fibrotest. The agreement and correlation between US scoring and fibrosis stages (by Fibrotest) was the target of our study.

\section{Assignment of US scoring of liver fibrosis}

We have summarized the determined US scoring of liver fibrosis among the studied cases in Table 1. Scores 4 and 6 were the most frequent diagnosis representing (24\% and 20\% respectively) (Figs. 1, 2, 3 , 4, and 5).

Shear wave elastography cutoff values were $1.35 \mathrm{~m} / \mathrm{s}$, $5.48 \mathrm{KPa}$ for $(\mathrm{F}>0) ; 1.66 \mathrm{~m} / \mathrm{s}, 8.29 \mathrm{kPa}$ for $(\mathrm{F}>1) ; 1.77 \mathrm{~m} / \mathrm{s}$, $9.40 \mathrm{kPa}$ for $(\mathrm{F}>2)$; and $1.99 \mathrm{~m} / \mathrm{s}, 11.9 \mathrm{kPa}$ for $(F>3)$.

Many associated abdominal ultrasound findings were detected in the studied patients such as splenomegaly $(20 \%)$, ascites $(16 \%)$, dilated portal vein $(16 \%)$, GB stones (28\%), liver hemangiomas, and simple cysts (8\%).

\section{Liver stiffness estimate by Fibrotest}

We have summarized the (F) stages of liver fibrosis among the studied cases in (Table 2). 


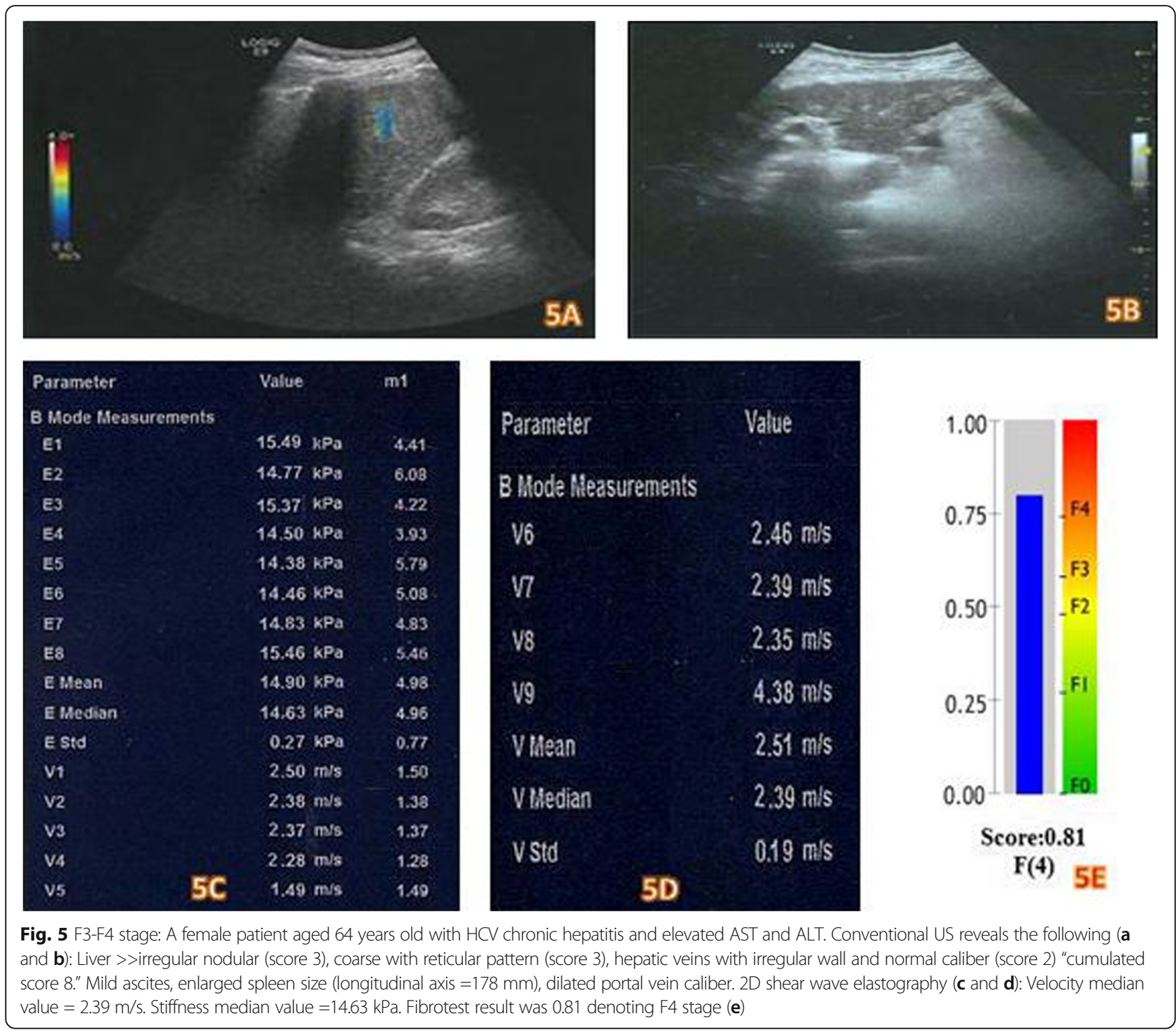

\section{Discordance between SWE and Fibrotest in fibrosis}

\section{staging}

Analysis of the results in term of liver fibrosis staging showed a discordance between the 2D-SWE and Fibrotest findings in $6 / 50(12 \%)$ of patients. Of these, $3(6 \%)$ patients were cardiac and cannot withhold breath during SWE while 2 (4\%) had hemolytic disorders and 1 (2\%) had Gilbert syndrome which affect the results of Fibrotest.

The agreement between shear wave elastography and Fibrotest in staging liver fibrosis

An excellent agreement was found between shear wave elastography and Fibrotest in staging of liver fibrosis in $88 \%$ of patients $\left(\kappa_{\mathrm{w}}=0.943,95 \% \mathrm{CI}, 0.88\right.$ to 1.00$)$ achieving a highly statistical significance $(P<0.001)$ (Table 3$)$.
Table 2 Results of Fibrotest and liver enzymes

\begin{tabular}{|c|c|c|}
\hline & \multicolumn{2}{|c|}{$(N=50)$} \\
\hline & No. & $\%$ \\
\hline \multicolumn{3}{|l|}{ Fibrotest results } \\
\hline Fo/F0-F1 & 6 & 12 \\
\hline F1/F1-F2 & 12 & 24 \\
\hline F2/F2-F3 & 18 & 36 \\
\hline F3/F3-F4/F4 & 14 & 28 \\
\hline \multicolumn{3}{|l|}{ ALT (IU/L) } \\
\hline$<40$ & 12 & 24 \\
\hline $40-80$ & 20 & 40 \\
\hline$>80$ & 18 & 36 \\
\hline \multicolumn{3}{|l|}{ AST (IU/L) } \\
\hline$<37$ & 16 & 32 \\
\hline $37-80$ & 22 & 44 \\
\hline$>80$ & 12 & 24 \\
\hline
\end{tabular}


Table 3 Degree of agreement between results of elastography and Fibrotest

\begin{tabular}{|c|c|c|c|c|c|}
\hline \multirow{3}{*}{$\begin{array}{l}\text { Fibrotest } \\
\text { Stage }\end{array}$} & \multicolumn{4}{|c|}{ Shear wave elastography } & \multirow[t]{3}{*}{$n, \%$} \\
\hline & \multicolumn{4}{|l|}{ Stage } & \\
\hline & Fo & $\mathrm{F} 1$ & F2 & F3-F4 & \\
\hline Fo & 6 & 0 & 0 & 0 & $6(12 \%)$ \\
\hline F1 & 2 & 10 & 0 & 0 & $12(24 \%)$ \\
\hline F2 & 0 & 2 & 14 & 2 & $18(36 \%)$ \\
\hline F3-F4 & 0 & 0 & 0 & 14 & $14(28 \%)$ \\
\hline$n, \%$ & $8(16 \%)$ & $12(24 \%)$ & $14(28 \%)$ & $16(32 \%)$ & $50(100 \%)$ \\
\hline Weighted kappa $\left(k_{\mathrm{w}}\right)$ & \multicolumn{4}{|l|}{0.943} & \\
\hline$P$ value & \multicolumn{4}{|l|}{$<0.001$} & \\
\hline Standard error & \multicolumn{4}{|l|}{0.03} & \\
\hline $95 \% \mathrm{Cl}$ & \multicolumn{4}{|c|}{0.88 to 1.000} & \\
\hline
\end{tabular}

The concordance between shear wave elastography (2DSWE) and Fibrotest and liver enzymes levels

There was a significant moderate positive concordance between US scoring and staging by 2D-SWE and staging by Fibrotest $\left(r_{s}, 0.49 ; P<0.01\right)$ and $\left(r_{s}, 0.48 ; P<0.01\right)$ respectively. However, no significant concordances were noticed between staging by AST and ALT and 2D-SWE and staging by Fibrotest $(P>0.05)$ (Table 4$)$.

\section{The diagnostic performance of conventional US and 2D-} SWE

2D shear wave elastography showed better diagnostic performance than visual assessment by conventional US for detection of chronic liver diseases (sensitivity 93\%, specificity $90 \%, P<0.01$, AUROC 0.9 ) as well as for evaluation of their severity and prognosis.

\section{Discussion}

In the current study, chronic viral hepatitis mostly affects men in the fifth decade of life and the most common symptoms of chronic viral hepatitis were vague abdominal pain and flu-like symptoms presenting in $28 \%$ of the included patients, this was in agreement with Gomaa A et al. [27].

Table 4 Degree of concordance between shear wave elastography (2D-SWE) and Fibrotest and liver enzymes levels in the studied patients

\begin{tabular}{llll}
\hline Variables & & Staging by 2D-SWE & Staging by Fibrotest \\
\hline AST (U/L) & $\boldsymbol{r}_{\boldsymbol{s}}$ & -0.007 & 0.105 \\
& $\boldsymbol{P}$ & 0.97 & 0.62 \\
ALT (U/L) & $\boldsymbol{r}_{\boldsymbol{s}}$ & 0.013 & 0.144 \\
& $\boldsymbol{P}$ & 0.95 & 0.49 \\
US scoring & $\boldsymbol{r}_{\boldsymbol{s}}$ & 0.49 & 0.48 \\
& $\boldsymbol{P}$ & $\mathbf{0 . 0 1 7}$ & $\mathbf{0 . 0 1 5}$ \\
\hline
\end{tabular}

$r_{s}$ Spearman's rho correlation
Sixty-four percent (64\%) of the included patients had chronic hepatitis $\mathrm{C}$ while $36 \%$ had chronic hepatitis $\mathrm{B}$, and in agreement with Dai CY et al. [28] and Chang et al. [29], the most frequent associated US finding during routine examination was GB stones (28\%).

We measured the degree of agreement between the results of Fibrotest and shear wave elastography for all included patients using weighted kappa test and there was a highly statistically significant agreement between SWE and Fibrotest $\left(\kappa_{\mathrm{w}}=0.943,95 \%\right.$ CI, 0.88 to 1.00$)(P<0.001)$. The strength of agreement was excellent.

According to the studies of Castera L et al. [30] and Poynard T et al. [31], the elastograhy-Fibrotest combination could be used reliably for first-line pre-therapeutic evaluation of fibrosis in HCV-infected patients, as they found that when FT and elastography agreed, their results concorded with the histopathologic results; this came in agreement with $88 \%$ of patients in our study. They also suggested that most discordant results between FT and liver biopsy were caused by biopsy examination failure. In our study, we can state that liver biopsy was of no use in $88 \%$ of our patients while the combination of elastograhy and Fibrotest gave best diagnostic performance in detecting the degree of fibrosis non-invasively.

Among the remaining $12 \%$ of our patients who had different fibrosis stages by elastography and Fibrotest, there were three cardiac patients $(6 \%)$ who cannot take sufficient breath hold leading to a non-homogeneous color box and inaccurate elastography results. Also, the results of Fibrotest were affected by the hemolytic disorders and Gilbert syndrome in the other three patients.

In our study, there were no significant concordances between staging by AST and ALT and staging by 2DSWE and Fibrotest $(P>0.05)$. This finding is consistent with the results of Serag WM and Elsayed BE [32] and Shiha G et al. [33] who reported that although a serum 
ALT level can correlate with the grades of liver necroinflammatory activity, it cannot serve as a parameter to assess the liver damage in patients with chronic hepatitis $\mathrm{C}$ and $\mathrm{B}$.

We have found a significant moderate positive concordance between US scoring and staging by Fibrotest $(P<0.05)$ indicating that US scoring correlates to the fibrosis stages but less than elastography quantification does, this was in agreement with the study of Kim SU et al. [10] who stated that elastography exhibited higher sensitivity and diagnostic accuracy for detection of chronic liver disease and more accurately reflected the severity of liver fibrosis over conventional B-mode US.

The major weak point of this study is that the 2D SWE results were not compared with histologic liver fibrosis stage. Nguyen D and Talwalkar JA [34] and Lackner $\mathrm{C}$ et al. [35] stated in their studies that if direct and indirect biomarkers provide a clear assessment of hepatic fibrosis with a combination of noninvasive methods like elastography, then further assessment by liver biopsy is generally not needed. Moreover, the study of Poynard $\mathrm{T}$ et al. [36] compared between two types of elastography using the Fibrotest as reference. Another limitation of this study is that we use only three parameters (liver surface nodularity, parenchymal echotexture, and hepatic vein contour) for ultrasound scoring system as we aimed to estimate how sensitive routine US examination and elastography could discriminate chronic liver disease from normal liver and how accurately each method could predict the severity of chronic liver disease, also, although the addition of the secondary quantifiable US findings such as portal vein flow velocity, hepatic venous flow, and caudate hypertrophy might improve the diagnostic performance of our US scoring system in predicting severe fibrosis or cirrhosis; it might not significantly affect the sensitivity for detecting chronic liver disease as stated by Colli A et al. [37].

\section{Conclusion}

Two-dimensional shear wave elastography showed a better diagnostic performance than conventional US alone for detection of chronic liver diseases and an excellent agreement with Fibrotest in detecting the degree of liver fibrosis and hence can be used reliably for non-invasive pre-therapeutic evaluation of fibrosis in HBV- and HCV-infected patients.

\section{Abbreviations}

2D SWE: Two-dimensional shear wave elastography; ALT: Alanine aminotransferase; AST: Aspartate aminotransferase; ARFI: Acoustic radiation force impulse; BMI: Body mass index; HBV: Hepatitis B virus; HCV: Hepatitis C virus; FT: Fibrotest; ROI: Region of interest; TE: Transient elastography

\section{Acknowledgements}

We would like to express our special thanks of gratitude to Prof. Dr. Osama Dawoud for his assistance in interpreting our findings.

\section{Authors' contributions}

A. Alsowey carried out the study concept and designed and drafted the manuscript. S. Shehata carried out the process of literature search and participated in the design of the study. A. Alsowey performed the statistical analysis. The authors read and approved the final manuscript.

\section{Funding}

Not applicable.

\section{Availability of data and materials}

The study included 50 patients referred to Radio-diagnosis Department, Faculty of Medicine, Zagazig University; from the tropical and internal medicine departments (30 males and 20 females), their ages ranged from 30 to 65 years from October 2019 to June 2020.

\section{Declarations}

Ethics approval and consent to participate

This study was approved by the Institutional Review Board (IRB) of Zagazig University. A written informed consents from all patients before the study were filled and signed, which are also approved by the Institutional Review Board (IRB) of Zagazig University with reference number: 4101.

\section{Consent for publication}

All patients included in this research gave written informed consent to publish the data contained within this study.

\section{Competing interests}

The authors declare that they have no competing interests.

Received: 19 November 2020 Accepted: 25 April 2021

Published online: 06 May 2021

\section{References}

1. Gharibvand MM, Asare M, Motamedfar A, Alavinejad P, Momeni M (2020) Ultrasound shear wave elastography and liver biopsy to determine liver fibrosis in adult patients. J Fam Med Prim Care 9(2):943-949. https://doi. org/10.4103/jfmpc.jfmpc_828_19 PMID: 32318450; PMCID: PMC7113977

2. Osman AM, El Shimy A, Abd El Aziz MM (2020) 2D shear wave elastography (SWE) performance versus vibration-controlled transient elastography (VCTE/ fibroscan) in the assessment of liver stiffness in chronic hepatitis. Insights Imaging 11(1):38. https://doi.org/10.1186/s13244-020-0839-y PMID: 32152802; PMCID: PMC7062958

3. Baranova A, Lal P, Birerdinc A, Younossi ZM (2011) Non-invasive markers for hepatic fibrosis. BMC Gastroenterol 11:91. https://doi.org/10.1186/1471-23 OX-11-91 PMID: 21849046; PMCID: PMC3176189

4. Bravo AA, Sheth SG, Chopra S (2001) Liver biopsy. N Engl J Med. 344(7):495500. https://doi.org/10.1056/NEJM200102153440706 PMID: 11172192

5. Roulot D, Costes JL, Buyck JF, Warzocha U, Gambier N, Czernichow S, Le Clesiau H, Beaugrand M (2011) Transient elastography as a screening tool for liver fibrosis and cirrhosis in a community-based population aged over 45 years. Gut. 60(7):977-984. https://doi.org/10.1136/gut.2010.221382 Epub 2010 Nov 10. PMID: 21068129

6. Castéra L, Foucher J, Bernard PH, Carvalho F, Allaix D, Merrouche W, Couzigou P, de Lédinghen V (2010) Pitfalls of liver stiffness measurement: a 5-year prospective study of 13,369 examinations. Hepatology. 51(3):828-835. https://doi.org/10.1002/hep.23425 PMID: 20063276

7. Fu J, Wu B, Wu H, Lin F, Deng W (2020) Accuracy of real-time shear wave elastography in staging hepatic fibrosis: a meta-analysis. BMC Med Imaging 20(1):16. https://doi.org/10.1186/s12880-020-0414-5 PMID: 32046659; PMCID: PMC7014748

8. Akay S, Karasu Z, Noyan A, Pala S, Musoglu A, Ilter T, Batur Y (2007) Liver biopsy: is the pain for real or is it only the fear of it? Dig Dis Sci. 52(2):579581. https://doi.org/10.1007/s10620-006-9493-6 Epub 2007 Jan 9. PMID: 17211704 
9. Bedossa P, Dargère $D$, Paradis V (2003) Sampling variability of liver fibrosis in chronic hepatitis C. Hepatology. 38(6):1449-1457. https://doi.org/10.1016/j. hep.2003.09.022 PMID: 14647056

10. Kim SU, Jang HW, Cheong JY, Kim JK, Lee MH, Kim DJ, Yang JM, Cho SW, Lee KS, Choi EH, Park YN, Han K-H (2011) The usefulness of liver stiffness measurement using FibroScan in chronic hepatitis $\mathrm{C}$ in South Korea: a multicenter, prospective study. J Gastroenterol Hepatol. 26(1):171-178. https://doi.org/10.1111/j.1440-1746.2010.06385.x

11. Chimoriya R, Piya MK, Simmons D, Ahlenstiel G, Ho V (2020) The use of twodimensional shear wave elastography in people with obesity for the assessment of liver fibrosis in non-alcoholic fatty liver disease. J Clin Med 10(1):95. https://doi.org/10.3390/jcm10010095 PMID: 33383965; PMCID: PMC7795317

12. Li C, Zhang C, Li J, Huo H, Song D (2016) Diagnostic accuracy of real-time shear wave elastography for staging of liver fibrosis: a meta-analysis. Med Sci Monit 22:1349-1359. https://doi.org/10.12659/msm.895662 PMID: 27102449: PMCID: PMC4844274

13. Myers RP, Elkashab M, Ma M, Crotty P, Pomier-Layrargues G (2010) Transient elastography for the noninvasive assessment of liver fibrosis: a multicentre Canadian study. Can J Gastroenterol 24(11):661-670. https://doi.org/10.11 55/2010/153986 PMID: 21157581; PMCID: PMC3004419

14. Furlan A, Tublin ME, Yu L, Chopra KB, Lippello A, Behari J (2020) Comparison of $2 \mathrm{D}$ shear wave elastography, transient elastography, and MR elastography for the diagnosis of fibrosis in patients with nonalcoholic fatty liver disease. AJR Am J Roentgenol. 214(1):W20-W26. https://doi.org/1 0.2214/AJR.19.21267 Epub 2019 Nov 12. PMID: 31714842

15. Ogawa E, Furusyo N, Murata M, Ohnishi H, Toyoda K, Taniai H, Ihara T, Ikezaki H, Hayashi T, Kainuma M, Hayashi J (2011) Longitudinal assessment of liver stiffness by transient elastography for chronic hepatitis B patients treated with nucleoside analog. Hepatol Res. 41(12):1178-1188. https://doi. org/10.1111/j.1872-034X.2011.00869.x Epub 2011 Sep 15. PMID: 21917085

16. Sporea I, Bota S, Peck-Radosavljevic M, Sirli R, Tanaka H, lijima H, Badea R, Lupsor M, Fierbinteanu-Braticevici C, Petrisor A, Saito H, Ebinuma H, Friedrich-Rust M, Sarrazin C, Takahashi H, Ono N, Piscaglia F, Borghi A, D'Onofrio M, Gallotti A, Ferlitsch A, Popescu A, Danila M (2012) Acoustic Radiation force impulse elastography for fibrosis evaluation in patients with chronic hepatitis C: an international multicenter study. Eur J Radiol 81(12): 4112-4118. https://doi.org/10.1016/j.ejrad.2012.08.018 Epub 2012 Sep 20. PMID: 23000186

17. Takahashi H, Ono N, Eguchi Y, Eguchi T, Kitajima Y, Kawaguchi Y, Nakashita S, Ozaki I, Mizuta T, Toda S, Kudo S, Miyoshi A, Miyazaki K, Fujimoto K (2010) Evaluation of acoustic radiation force impulse elastography for fibrosis staging of chronic liver disease: a pilot study. Liver Int. 30(4):538-545. https://doi.org/10.1111/j.1478-3231.2009.02130.x

18. Stasi C, Milani S (2017) Evolving strategies for liver fibrosis staging: noninvasive assessment. World J Gastroenterol 23(2):191-196. https://doi.org/1 0.3748/wjg.v23.i2.191 PMID: 28127192; PMCID: PMC5236498

19. Guibal A, Renosi G, Rode A, Scoazec JY, Guillaud O, Chardon L, Munteanu M, Dumortier J, Collin F, Lefort T (2016) Shear wave elastography: an accurate technique to stage liver fibrosis in chronic liver diseases. Diagn Interv Imaging. 97(1):91-99. https://doi.org/10.1016/j.diii.2015.11.001 Epub 2015 Dec 3. PMID: 26655870

20. Friedrich-Rust M, Rosenberg W, Parkes J, Herrmann E, Zeuzem S, Sarrazin C (2010) Comparison of ELF, FibroTest and FibroScan for the non-invasive assessment of liver fibrosis. BMC Gastroenterol 10:103. https://doi.org/10.11 86/1471-230X-10-103 PMID: 20828377; PMCID: PMC2944336

21. Halfon P, Munteanu M, Poynard T (2008) FibroTest-ActiTest as a noninvasive marker of liver fibrosis. Gastroenterol Clin Biol. 32(6 Suppl 1):22-39. https://doi.org/10.1016/S0399-8320(08)73991-5 PMID: 18973844

22. Kim JE, Lee JY, Kim YJ, Yoon JH, Kim SH, Lee JM, Han JK, Choi BI (2010) Acoustic radiation force impulse elastography for chronic liver disease: comparison with ultrasound-based scores of experienced radiologists, ChildPugh scores and liver function tests. Ultrasound Med Biol. 36(10):1637-1643. https://doi.org/10.1016/j.ultrasmedbio.2010.07.016 PMID: 20800940

23. LOGIQ E9 shear wave elastography (2015): global white paper shears wave elastography. https://sonoworld.com/Common/DownloadFile.a spx?ModuleDocumentsld=83. Accessed Mar 2015.

24. Shiina T, Nightingale KR, Palmeri ML, Hall TJ, Bamber JC, Barr RG, Castera L, Choi Bl, Chou YH, Cosgrove D, Dietrich CF, Ding H, Amy D, Farrokh A, Ferraioli G, Filice C, Friedrich-Rust M, Nakashima K, Schafer F, Sporea I, Suzuki S, Wilson S, Kudo M (2015) WFUMB guidelines and recommendations for clinical use of ultrasound elastography: Part 1: basic principles and terminology. Ultrasound Med Biol. 41(5):1126-1147. https:// doi.org/10.1016/j.ultrasmedbio.2015.03.009 Epub 2015 Mar 21. PMID: 25805059

25. Abrams GA, Jamal H, Deeter WT 3rd, Patil N (2016) LOGIQ E9 shear wave elastrography for detection of liver fibrosis in patients with chronic hepatitis C virus. South Med J 109(11):730-734. https://doi.org/10.14423/SMJ. 0000000000000562 PMID: 27812720

26. Ratziu V, Massard J, Charlotte F, Messous D, Imbert-Bismut F, Bonyhay L, Tahiri M, Munteanu M, Thabut D, Cadranel JF, Le Bail B, de Ledinghen V, Poynard T, LIDO Study Group (2006) CYTOL study group. Diagnostic value of biochemical markers (FibroTest-FibroSURE) for the prediction of liver fibrosis in patients with non-alcoholic fatty liver disease. BMC Gastroenterol 6:6. https://doi.org/10.1186/1471-230X-6-6 PMID: 16503961; PMCID: PMC1386692

27. Gomaa A, Allam N, Elsharkawy A, El Kassas M, Waked I (2017) Hepatitis C infection in Egypt: prevalence, impact and management strategies. Hepat Med 9:17-25. https://doi.org/10.2147/HMER.S113681 Erratum in: Hepat Med. 2017 Jul 26;9:35. PMID: 28553150; PMCID: PMC5439968

28. Dai CY, Lin Cl, Yeh ML, Hsieh MH, Huang CF, Hou NJ, Hsieh MY, Huang JF, Lin ZY, Chen SC, Wang LY, Chang WY, Chen JS, Yu ML, Chuang WL (2013) Association between gallbladder stones and chronic hepatitis $C$ : ultrasonographic survey in a hepatitis $C$ and $B$ hyperendemic township in Taiwan. Kaohsiung J Med Sci. 29(8):430-435. https://doi.org/10.1016/j.kjms.2 012.12.004 Epub 2013 Feb 20. PMID: 23906233

29. Chang TS, Lo SK, Shyr HY, Fang JT, Lee WC, Tai DI, Sheen IS, Lin DY, Chu CM, Liaw YF (2005) Hepatitis C virus infection facilitates gallstone formation. J Gastroenterol Hepatol. 20(9):1416-1421. https://doi.org/10.1111/j.1440-174 6.2005.03915.x PMID: 16105130

30. Castera L, Forns $X$, Alberti A (2008) Non-invasive evaluation of liver fibrosis using transient elastography. J Hepatol. 48(5):835-847. https://doi.org/10.101 6/j.jhep.2008.02.008 Epub 2008 Feb 26. PMID: 18334275

31. Poynard T, Munteanu M, Imbert-Bismut F, Charlotte F, Thabut D, Le Calvez S, Messous D, Thibault V, Benhamou Y, Moussalli J, Ratziu V (2004) Prospective analysis of discordant results between biochemical markers and biopsy in patients with chronic hepatitis C. Clin Chem. 50(8):1344-1355. https://doi.org/10.1373/clinchem.2004.032227 Epub 2004 Jun 10. PMID: 15192028

32. Serag WM, Elsayed BE (2021) Detection of liver fibrosis stages in patients with hepatitis C virus infection by non-invasive tool. Egypt Liver Journal. 11(1):9. https://doi.org/10.1186/s43066-021-00076-w

33. Shiha G, Aboud A, Khalil DM, Sieddek AS (2019) Comparison between transient elastography and other markers for predicting the fibrosis stages of patients with chronic HCV infection in Beni-Suef governorate, Egypt. Med J Viral Hepatitis 4(1):45-52 https://mjvh.journals.ekb.eg/article_59526_94c4 db6be74e86e15623049d154d3cef.pdf

34. Nguyen D, Talwalkar JA (2011) Noninvasive assessment of liver fibrosis. Hepatology. 53(6):2107-2110. https://doi.org/10.1002/hep.24401 PMID: 21547935

35. Lackner C, Struber G, Liegl B, Leibl S, Ofner P, Bankuti C, Bauer B, Stauber RE (2005) Comparison and validation of simple noninvasive tests for prediction of fibrosis in chronic hepatitis C. Hepatology. 41(6):1376-1382. https://doi. org/10.1002/hep.20717 PMID: 15915455

36. Poynard T, Munteanu M, Luckina E, Perazzo H, Ngo Y, Royer L, Fedchuk L, Sattonnet F, Pais R, Lebray P, Rudler M, Thabut D, Ratziu V (2013) Liver fibrosis evaluation using real-time shear wave elastography: applicability and diagnostic performance using methods without a gold standard. J Hepatol. 58(5):928-935. https://doi.org/10.1016/j.jhep.2012.12.021 Epub 2013 Jan 12. PMID: 23321316

37. Colli A, Fraquelli M, Andreoletti M, Marino B, Zuccoli E, Conte D (2003) Severe liver fibrosis or cirrhosis: accuracy of US for detection--analysis of 300 cases. Radiology. 227(1):89-94. https://doi.org/10.1148/radiol.2272020193 Epub 2003 Feb 19. PMID: 12601199

\section{Publisher's Note}

Springer Nature remains neutral with regard to jurisdictional claims in published maps and institutional affiliations. 